https://helda.helsinki.fi

\title{
Coconstructing in conversations using a communication book
}

\author{
Savolainen, Irina
}

2018

Savolainen , I , Klippi , A \& Launonen , K 2018 , ' Coconstructing in conversations using a communication book ' , Journal of Interactional Research in Communication Disorders, vol. 9 , no. 2 . https://doi.org/10.1558/jircd.36668

http://hdl.handle.net/10138/333371

https://doi.org/10.1558/jircd.36668

unspecified

acceptedVersion

Downloaded from Helda, University of Helsinki institutional repository.

This is an electronic reprint of the original article.

This reprint may differ from the original in pagination and typographic detail.

Please cite the original version. 


\title{
Coconstructing in Conversations Using a Communication Book
}

Irina Savolainen, Anu Klippi, and Kaisa Launonen

University of Helsinki, Finland

\begin{abstract}
This study describes the multiple coconstruction process of aided utterances that ocuur when nonspeaking people use a communication book in their everyday conversations. Previous studies have shown that coconstruction is present both in the progress of pointing-voicing pairs and in the negotiation of meanings. Adopting the concepts and the tools of multimodal conversation analysis, this study demonstrates how two non-speaking boys and their speech and language therapists utilized simultaneously six interactional resources that were interwoven in different multimodal practices during their coconstruction of aided utterances. The observations elicited by microanalysis provide an insight into the temporal, co-operative and progressive nature of conversations that are coconstructed with a communication book. The findings of this study are helpful for professionals in assessing and scaffolding aided communicators during their conversations with their significant communicative partners.
\end{abstract}

Keywords: COCONSTRUCTION; AIDED CONVERSATION; SOCIAL ACTION; INTERACTIONAL RESOURCES; MULTIMODALITY: SYNCHRONIZATION

\section{Introduction}

Nonspeaking people use different augmentative and alternative communication (AAC) means to replace their missing speech. In aided conversations, nonspeaking people use either technical or nontechnical communication aids, and in unaided conversations, they communicate without aids, such as by using manual signs (e.g., Lloyd \& Blischak, 1992). One of the nontechnical aided means is a communication book and it usually consists of hundreds or even thousands of symbols. A nonspeaking person uses a communication book to produce utterances by pointing to the symbols, and a speaking partner vocalises them. During conversations that use nontechnical communication aids, this coconstruction between aided communicators and speaking partners is emphasised. On the one hand, the coconstruction is present structurally in pointing voicing units, which also affects the speed of the conversations, making them slow (Bloch, 2005; Sigurd Pilesjö \& Rasmussen, 2011). On the other hand, the coconstruction is present when the participants negotiate the meaning of the symbol pointings (von Tetzchner \& Martinsen, 1996; Koivunen, 2012).

According to conversation analysis (CA), conversationalists jointly cooperate to coconstruct a social action for each turn, and it is not solely the speaker who decides the meaning of an utterance (Schegloff, 2007). The social action is therefore a composite, which (a) all participants develop by engaging in a multidimensional process, (b) can occur together with other social actions in one turn constructional unit, and (c) can be described on many levels (Schegloff, 2007; Enfield, 2013). Regarding the composite nature of the social action, researchers emphasise and use different terms to refer to the interactional resources and modalities that participants exploit in their coconstruction process of a social action (Enfield, 2013; Goodwin, 2000; Mondada, 2014, Ruusuvuori, 2013). Furthermore, the same concepts can be referred to by different terms across researchers, and even one term can be used with different meanings in the same article (Nevile, 2015). Some researchers 
focus on one interactional resource, such as Ruusuvuori (2013) in her studies on emotional displays. Others examine the phenomenon of coconstruction from a larger perspective (e.g., Clark's and Brennan's (1991) grounding, Goodwin's (2000) semiotic fields and resources; Enfield's (2013) authority and common ground or Levinson's (2013) action formation and ascription). Despite the different terms and approaches, CA researchers agree that within ongoing conversations, resources and modalities are intertwined and change according to the context (Goodwin, 2000; Mondada, 2014). During the coconstruction process, the speaker constructs an emerging utterance in terms of the recipient's activities, and the recipient is not passive, but identifies the form and the meaning of the utterance based on the speaker's multimodal signals (Goodwin, 2000). Participants show continued attention when they monitor each other's contributions during conversations in order to reach a mutual understanding (Clark \& Brennan, 1991). This sensitivity to the partner's actions begins in early development when newborn infants imitate the activities of their caregivers, such as by making single vocal sounds or extending a finger (Trevarthen \& Aitken, 2001).

Even though aided conversations are often characterised by their slowness and the imbalance of speaking turns in favor of the speaking partner (Clarke \& Kirton, 2003; Sundqvist, Plejert, \& Ronnberg, 2010; Auer \& Hörmeyer, 2017), both participants are orientated to progressivity (Higginbotham \& Wilkins, 1999; Savolainen, Klippi, Tykkyläinen, Higginbotham \& Launonen, submitted). The conversations are accomplished in a progression of social actions, sequences and turns similar as in spoken conversations (Sigurd Pilesjö \& Rasmussen, 2011). In the progressive construction of conversations using nontechnical communication aids, gaze plays an important role in beginning, maintaining and ending a turn. The conventional gaze practice at the beginning of the turn is a gaze shift to the communication aid (Sigurd Pilesjö, 2013). The pointing voicing process that follows utilises the communication book as a material modality, accomplished through the participant's multimodal actions. The book is inseparable from the interaction, as it would be using technological tools that may be embedded in interaction (see Heath \& Luft, 2013). During the coconstruction of an aided utterance, the communication book is in the focus of the participants' orientation because the aided communicators must see where they are pointing, and the speaking partners must follow their pointing in order to interpret and voice the symbols. Previous studies report that an aided communicator looks constantly at the nontechnical aid, but the speaking partner can turn her gaze between the aid and the aided communicator (Sigurd Pilesjö \& Rasmussen, 2011; Ferm, Ahlsén \& Björck-Åkesson, 2013). Aided communicators' continuous gaze to a communication aid can be treated as a method to show that an aided turn is in progress (Sigurd Pilesjö \& Rasmussen, 2011), but it may also decrease aided communicators' ability to follow the other multimodal means and lead to misunderstandings (Robillard, 1994). At the end of the aided utterance, the aided communicator shifts his or her gaze to the communication partner (Sigurd Pilesjö \& Rasmussen, 2011; Koivunen, 2012; Clarke, Bloch \& Wilkinson 2013). Within spoken conversations, participants predict the possible turn ending by utilising the syntax, prosody, gaze, and action of the turn (Levinson, 2013), but in aided conversations, the role of the gaze at the end of utterances is pronounced due to the aided communicators' lack of oral speech, and thus prosody (Clarke et al., 2013).

The co-operative nature of aided conversations has been increasingly the focus of AAC research during the latest decade, with research interest no longer focusing primarily on the role of the conversation partner or on the nonspeaking persons' abilities (Norén, Samuelsson \& Plejert, 2013). However, in the field of AAC research, only a few conversation analytic studies have been conducted on conversations using nontechnical communication aids (Sigurd Pilesjö, 2013; Sigurd Pilesjö \& Rasmussen, 2011; Norén \& Sigurd Pilesjö, 2016; Sigurd Pilesjö \& Norén, 2017). In fact, our literature search for studies conducted on conversations using a pragmatically organised 
communication book, which is the aid for the conversations in the present study, yielded only one master's thesis (Koivunen, 2012).

This study approaches the coconstruction process of aided utterances from two directions. Firstly, it will be demonstrated, from a larger perspective, how participants coconstruct their social actions in aided utterances. This study introduces, in relation to previous AAC research, six intertwined interactional resources that the participants apply in the coconstruction of social actions in conversation using a communication book. Secondly, microanalysis will be applied to visualise how participants synchronise their multimodal practices in the progress of the coconstruction. Our purpose is to illuminate how multidimensional and demanding the coconstruction of aided conversations are for both participants, and show, even so, how succesful, aided conversations are possible.

\section{Method}

\section{Participants}

The two nonspeaking participants in this study were male, one boy and one adolescent who are referred to as Jaakko, and Kalle, respectively (Table 1). They were selected from the data collected from the conversations of four aided communicators. The criteria for the selection of the conversations for this study were: 1) aided communicators used a communication book by pointing, and 2) the conversation situation did not include playing with toys nor handling other objects. To communicate in their daily interaction, Jaakko and Kalle used a pragmatically organised communication book and a speech generating device (SGD). While Kalle displayed a few manual signs, Jaakko did not. Both produced multiword aided utterances that were not always syntactically fully formed. Jaakko and Kalle studied in a special school for children and youths with physical disabilities and they each used a wheelchair. The speaking participants in this analysis were the two boys' speech and language therapists (SLT). Jaakko and his SLT had known each other since Jaakko was under two years old, and Kalle and his SLT had known each other for four years. Furthermore, the SLTs had many years' experience in using communication books to discuss with nonspeaking people. All the conversationalists as well as the principal of the participant's school granted their informed consent to participate in this study. For the participant who was under 18 years old, his parents also signed an informed consent. Ethical approval was obtained from the University of Helsinki Ethical Review Board in the Humanities and Social and Behavioural Sciences.

Table 1 Summary of aided communicators' characteristics

\begin{tabular}{lccccccc}
\hline Name & Age & GDV & CFCSb & Diagnosis & Speech & $\begin{array}{c}\text { Years of } \\
\text { using } \\
\text { CB }\end{array}$ & $\begin{array}{c}\text { Symbols } \\
\text { on opening } \\
\text { of book }\end{array}$ \\
\hline Jaakko & 18 & 12 & III & $\begin{array}{c}\text { Aicardi } \\
\text { goutieres } \\
\text { syndrome }\end{array}$ & $\begin{array}{c}\text { Some words } \\
\text { with vowels }\end{array}$ & 11 & $\begin{array}{c}48+ \\
\text { Symbols for } \\
\text { navigation }\end{array}$ \\
\hline Kalle & 10 & 0c & II-III $\begin{array}{c}\text { Arterial } \\
\text { ischemic stroke } \\
\text { of brainstem, } \\
\text { Tetra- and bulbar } \\
\text { paresis }\end{array}$ & Vocalising & 4 & $\begin{array}{c}\text { Symbols for } \\
\text { navigation }\end{array}$ \\
\hline
\end{tabular}


Note: Age in years in the period of video recordings. GDV = the Gap between Developmental and Verbal age in years. CFCS = Communication Function Classification System (Hidecker et.al., 2011). $\mathrm{CB}=$ communication book.

a Assessed by a psychologist, not measured for this research. bAssessed by the speech and language therapist who was responsible for the rehabilitation, not measured for this research. c According to one assessment, some of the verbal skills were at the same level as the developmental age, and the age level of the other verbal skills was not mentioned.

\section{Pragmatic Organised Communication Book}

In the conversations analysed in this study, both nonspeaking participants used a pragmatically organised communication book, called AACi1 books, the Finnish version of the book model "Pragmatic Organisation Dynamic Display" (PODD)2, and the content of the books was individualised to accommodate the boys' communication needs. The symbols were organised into 18 different categories based upon either topics (such as school) or word classes (such as a verb). Each opening of the book had symbols from different word classes, which were grouped and coded by colours. The grammatical symbols were used for the plural, genitive, and past tense, as well as a general symbol for inflections. The navigation between openings was achieved by pointing to the category symbols, the special navigation symbols (such as turn the page) and the predictably associated links (as in the symbol of GO, there was a link to the page PLACES). Both nonspeaking boys used the book by pointing with their finger/s to the symbols, and the SLT turned a page when needed.

\section{Procedures}

The data for this study are drawn from three aided conversations between the boys and their SLTs. The participants were requested to engage in a free conversation on a topic of their own choice. The duration of the conversation was not specified, and they varied from 29 minutes to 60 minutes. The participants sat side by side at the table and decided on the seating arrangements themselves before the recording. All conversations were recorded by a single video camera, which the therapists set up to display, at least, the top part of the body of both participants and the communication book.

\section{Data Analysis and Selection of Excerpts}

The conversation analytic research proceeded in five phases. The first phase involved the identification of distinctive behaviours in the data from the pervasive co-occurring multimodal actions that occurred in their conversations using a communication book. We introduced part of the data in a nonmotivated data session consisting of six researchers who were familiar with CA and had used it in analysing conversations of people with disabilities (see the structure and purpose of data sessions Stevanovic \& Weiste, 2017). The discussion in the data session focused on the richness of different multimodal practices and their positions in a sequence.

During the second phase, we collected the sequences. For the sake of uniformity, we selected from both boys' conversations the first ten sequences, in which aided utterances contained at least two graphic symbols but no misunderstandings, storytelling or enumerating, and the role of the SLT was not institutional, which means that the SLTs neither had a goal for the conversation nor restricted the participation or actions of the nonspeaking participants during the sequences (see Heritage and Drew, 1992). Adopting these criteria, ten conversation sequences were collected from one of Kalle's conversations. To collect ten conversation sequences for Jakko, data were extracted from two different conversations with the same SLT.

Kalle varied in the number of pointing motions he displayed during the production process of the aided utterances. He pointed 2 to 14 times per utterance and 2 to 5 of these pointings referenced 
lexical symbols. The other pointings were navigation symbols, pragmatic starters (a question), letters or grammatical symbols (the past tense). Sequentially, six of the ten aided utterances were first pair parts, such as questions, and statements with new information or telling about previous events. The other four of the ten aided utterances were second pair parts, such as answers regarding Kalle's life or they exhibited general knowledge. In Jaakko's collection, Jaakko pointed 2 to 10 times per utterance, and 2 to 4 of his pointings referenced lexical symbols. The other pointings were navigation symbols. Sequentially, seven of the ten aided utterances were first pair parts, such as statements concerning his feelings, hopes or opinions, and three were second pair parts, such as his answers related to his life or opinions.

In the third phase, we used a professional tool for the creation of complex annotations on video and audio resources, ELAN3, to make annotations of the participants' multimodal actions in the sequences. The annotated multimodal actions used to analyse the data were comprehensive in 1) all participants' gaze and face, 2) the aided communicators' pointing and head movement and 3) the SLTs' voicing and activity. These annotations were made for both Kalle's and Jaakko's collections.

During the fourth phase, we conducted a microanalysis of the data (20 sequences) to determine the participants' generic practices and deviant cases (see Sidnell, 2013) at the beginning, the middle and the end of the aided utterance. To analyse these cases, we needed a theoretical tool to organize the observations of the coconstruction process. Toward this end, we consulted the CA literature and selected six interactional resources (linguistic meaning, sequential position of utterance, larger course of actions, displays of emotion, common ground and participants' roles), which describe best the coproducing process of the social action in the data for this study (see Enfield, 2013; Goodwin, 2000; Levinson, 2013, Ruusuvuori, 2013). In addition, we structured the coconstructing process in terms of two co-occurring circles (Figure 1). The inner circle consists of the multimodal situational practices that are deployed with strategic synchrony, by the participants, who are orienting to the progressivity of the conversations (see Mondada, 2014). The outer circle contains the multiple interactional resources that may be employed by the participants to coproduce a social action of an aided utterance. Both circles are active simultaneously, with the coproduction of a social action continuing during a speaking partner's turn. 


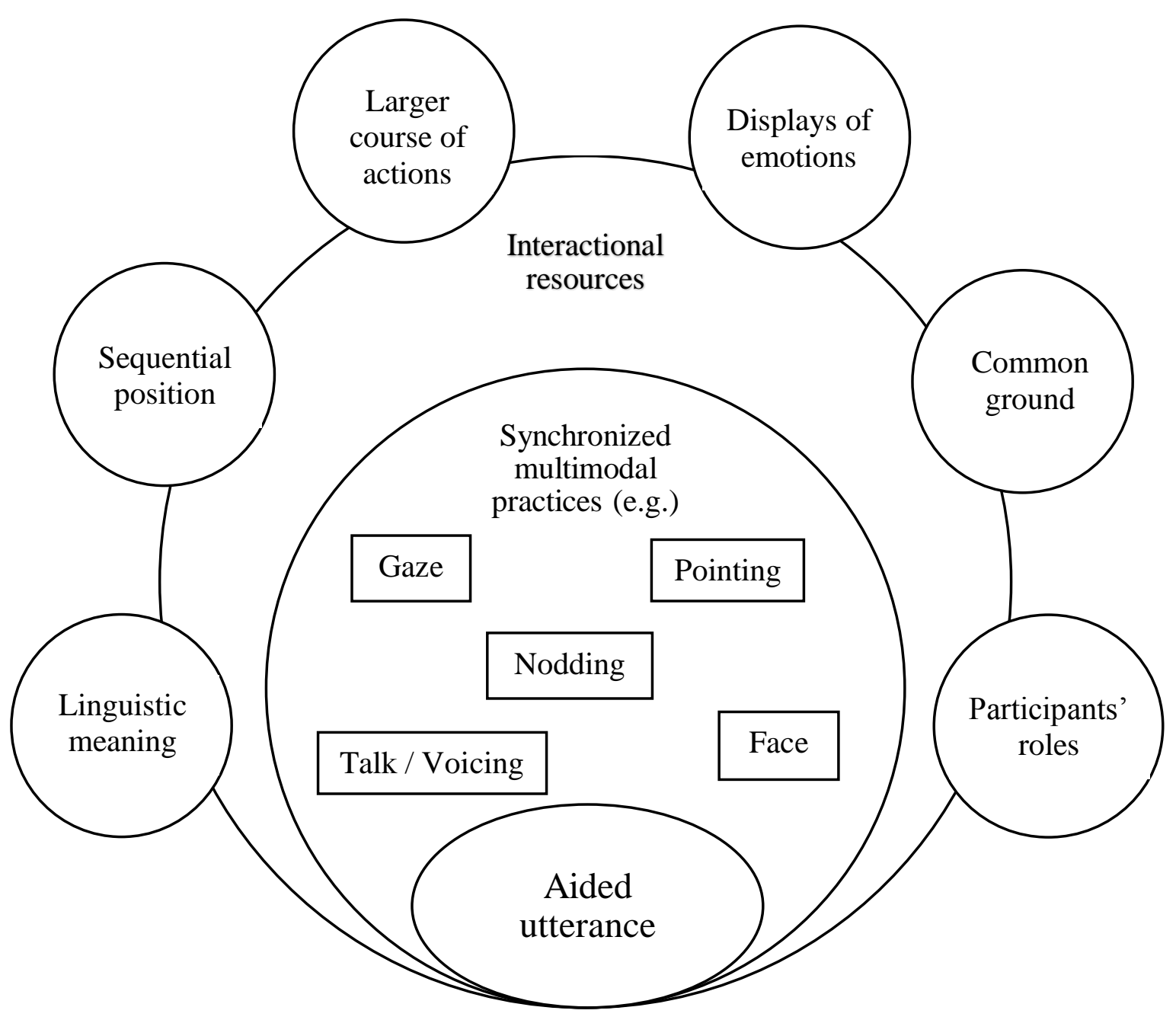

Figure 1. The theoretical tool that was created to analyse the coconstruction of an aided utterance. Participants simultaneously utilise different interactional resources in the outer circle and synchronise different multimodal situational practices in the inner circle.

The fifth phase consisted of selecting representative excerpts. In particular, we were interested in how participants flexibly and strategically coconstruct aided conversation. To that end, we wanted to examine exchanges that would provide clear examples of the use of interactional resources and the synchronization of multimodal practices. These excerpts were chosen from two of Jaakko's conversations, because they included several phenomena in the same sequence. Deriving both excerpts from Jaakko's collection, was not considered to weaken the transparency of the data, because the participants had mainly similar practices in Kalle's and Jaakko's conversations, and the observations of multimodal practices in Kalle's collections are referred to in the analysis.

The purpose of the first excerpt was to describe how the participants utilised different interactional resources (see the outer circle). For this reason, we selected the sequence in which the participants applied typical multimodal practices in their coconstruction process. The purpose of the second excerpt was to describe how the participants synchronised their multimodal actions during the coconstruction process (see the inner circle). For the second excerpt, we selected a sequence that involved the participants making more effort to advance their conversational progression than in the 
other sequences. These cases were verified in their suitability for the stated purposes in the aforementioned datasessions.

\section{Transcription}

The multimodal transcriptions of the excerpts followed the conventions proposed by Mondada (2014), and the notations are explained in the Appendix. The therapist was sitting in profile to a video camera, so the focus of her gaze was inferred from the position of her head. When transcribing, we introduced some new practices that were motivated by the data. Firstly, the voicings of the symbols are transcribed under the aided communicator's turn to emphasise the authorship of the aided utterance and the idea that no modality is more important than any other in human interaction (see Stivers \& Sidnell, 2005). Secondly, the time between multimodal actions was transcribed into the segments to separate them from pauses. Thirdly, an arrow indicated the multimodal actions that continued on the following line. When they continued over the following line, an arrow and a number of the line was used to simplify the display of transcriptions. The fourth new practice concerned transcribing multimodal actions by underlining so as to delineate the beginning and the end of the actions. When evaluating the data, readers need to remember that the length of an underline is not in proportion to the duration of real time.

\section{Results}

The analysis of the data will progress from a larger perspective to a microanalysis, and show how the participants "coordinate both the content and process of what they are doing" (Clark \& Brennan, 1991, p. 222). Firstly, by examining excerpt one, we introduce six intertwined interactional resources that constitute phenomena of the outer circle in the coconstructing of social action. Secondly, by focusing on the second excerpt, we describe how the coconstruction proceeds with synchronised multimodal practices in the inner circle.

\section{Interactional Resources}

Participants coconstruct the social action of an utterance by utilising several situational interactional resources, and the mutual interpretation of the social action is accomplished in the next turn(s) after the utterance (Schegloff, 2007). In the first excerpt, the participants apply at least six interactional resources to coconstruct the social action. The SLT treats Jaakko's aided utterance as a statement, which invites agreeing and confirming on a mother's love for her all children, and Jaakko confirms this.

Prior to this excerpt, Jaakko $(\mathrm{J})$ tells his big news that his mother is going to have a baby. The SLT (T) asks when the baby will be born, and Jaakko answers that it will be born in the autumn. There is a two second silence, and Jaakko then initiates a new first pair part of the sequence.

\section{Excerpt 1}

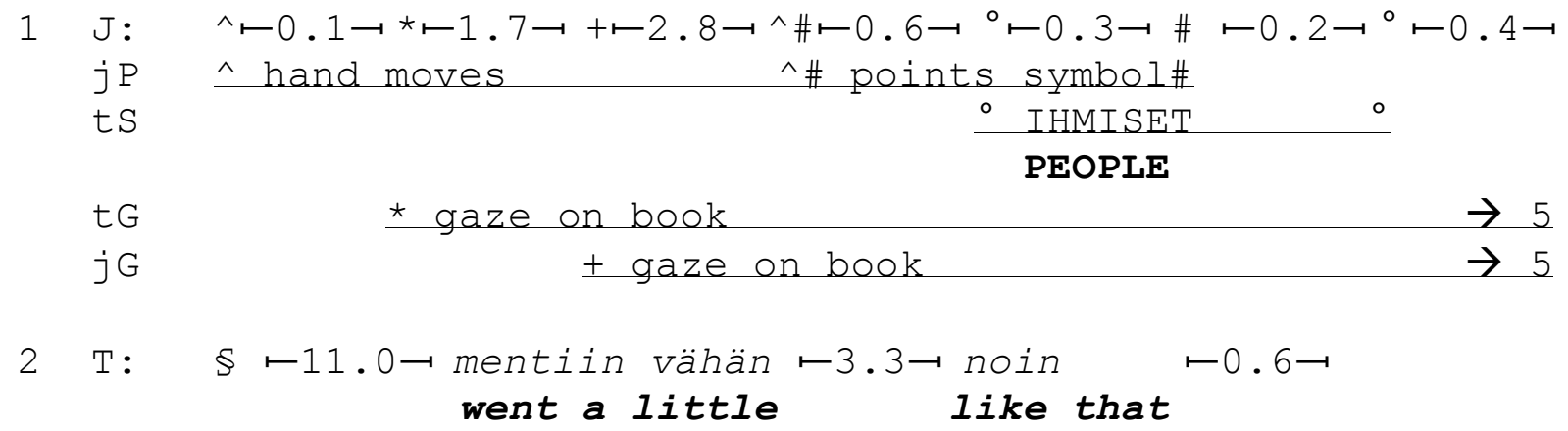




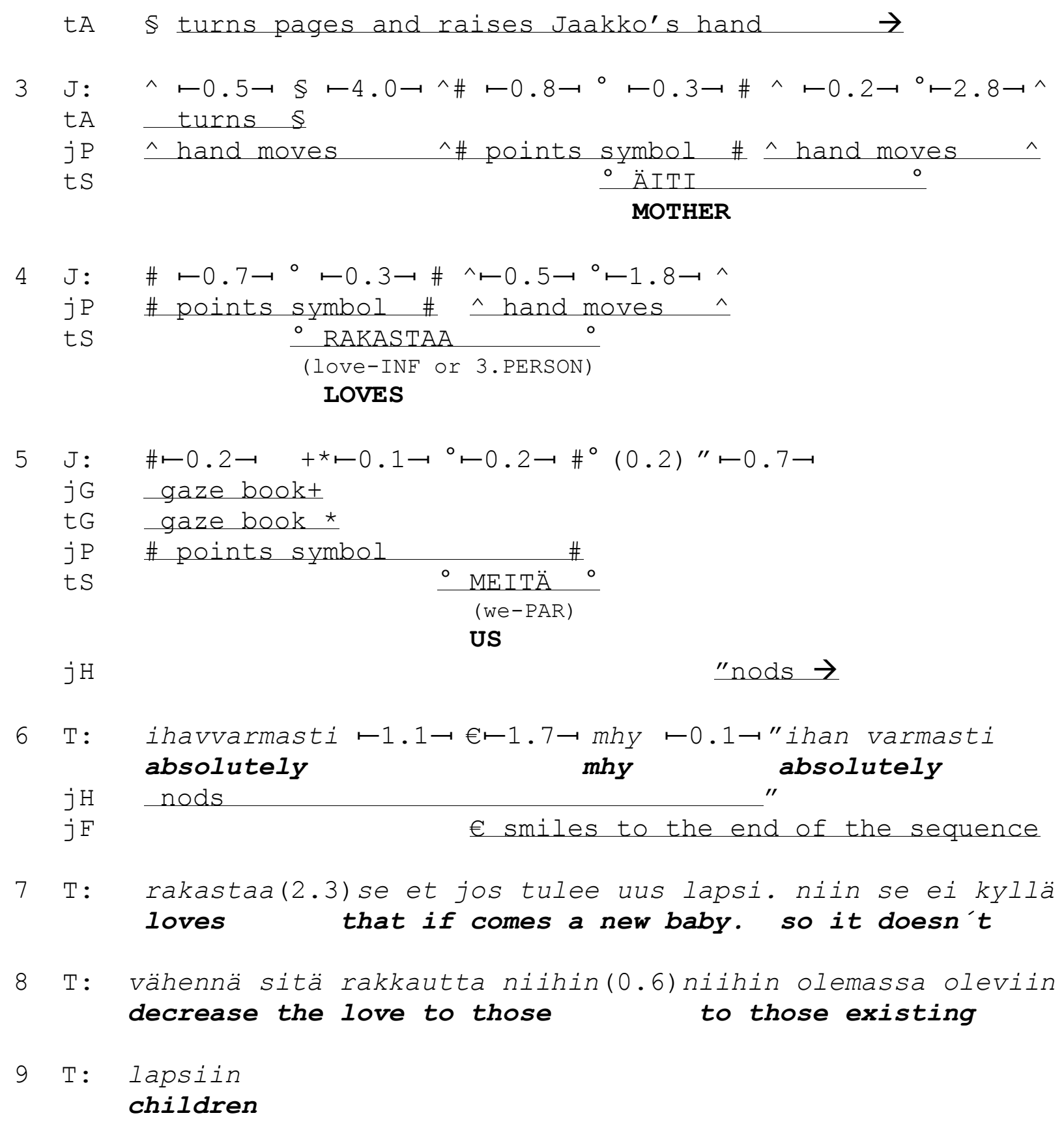

During conversations that use communication boards or books, the linguistic meaning is coconstructed through pointing voicing pairs (Sigurd Pilesjö \& Rasmussen, 2011; Koivunen, 2012; Bloch, 2005). In this excerpt, Jaakko points to symbols with the index finger of his right hand, and after he points, the SLT says aloud the linguistic label of the symbol, which is written above the symbol (Lines 1, 3, 4, 5). During this interaction, the SLT voices the two first symbols in their basic lexical forms of ÄITI RAKASTAA (mother loves) (Lines 4-5) (the Finnish verb RAKASTAA, (loves), is the same in the infinitive and in the third person form), but the form of the third symbol, MEITÄ (us), is inflected (Line 5). Jaakko's gaze shifts to the therapist during his pointing at the third symbol. This is a sign that it is the last symbol, and the SLT inflects the word WE to the form US to create a syntactically compound utterance. After a minimal pause, Jaakko confirms the voicings by nodding, and the therapist then begins her second pair part of the sequence (Line 6). The SLT in this excerpt does not produce a separate interpretation of the aided utterance, a practice which was also observed elsewhere in this study (see the second excerpt in line 32). Here the interpretation is embedded into the second pair part. 
Even if the aided utterance that MOTHER LOVES US is syntactically correct, its social action would be difficult to interpret without accessing other interactional resources. According to CA, the sequential position of a turn is one of the basic resources for participants to recognise the social actions of a turn (Schegloff, 2007). During aided conversations, speaking participants occasionally encounter troubles in recognising the position of an aided utterance in a sequence because it is syntactically unformed, or the speaking partner does not wait for the production process until the end (e.g., Sundqvist et al., 2010). In this excerpt, the position of Jaakko's utterance in the sequence is clear. The excerpt begins at the two second silence when the previous sequence has ended. Jaakko produces his syntactically complete first pair part (Lines 1-5), and the SLT allows him the time to produce it. At the end of his pointing at the last symbol, Jaakko yields the floor through his gaze for the second pair part, and the therapist produces it (Line 6-9).

An important aspect in ascribing social action is the position of a turn in a sequence, but social actions are always a part of the larger course of actions and this provides additional information and complements linguistic meaning (Goodwin, 2000). Aided conversations that utilise the larger context as an interactional resource are emphasised because aided utterances tend to be short. This can be an effect of a) the aided communicator's communicative competence, b) a presupposition that the speaking partner will complement the meaning, c) a lack of the vocabulary in the communication aid, d) using one symbol as whole utterance, e) the nature of the visual modality in aided communication or $\mathrm{f}$ ) speeding up the progress of an aided conversation (Binger \& Light, 2008; Todman et al., 2008; Rydeman \& Hedvall 2013). This excerpt features Jaakko producing the syntactically complete main clause, MOTHER LOVES US, but the meaning of this clause occurs only in the SLT's second pair part. In this situational context, the speech therapist utilises the larger context of the pregnant mother, which is an essential part of the process of ascription and understanding the social action. The SLT understands Jaakko's utterance as referring to a new baby to be born, which Jaakko does not explicitly state.

The participants' emotional displays reveal that they mutually understand the social action of Jaakko's utterance. As Ruusuvuori (2013, p 330) observes, "Emotional aspects of interaction, such as laugh tokens, an emotional tone of voice, affective lexical choices and /or facial expressions, are intertwined with spoken utterances and constitute an important resource for interpreting an action as emotional". In this excerpt, Jaakko introduces the conversational topic of a mother's love, which is a highly emotional theme. Jaakko and the SLT coproduce the aided utterance with no emotional displays other than the lexical choices until the last word, US (Lines 1-5). Thereafter, their gaze is mutual and Jaakko begins nodding (Line 5). During this phase, the participants shift from the production process to coconstructing, strong, emotional intersubjectivity. Although Jaakko cannot apply word prosody, he uses nodding, gaze and smiling (from Line 5 to the end) as emotional displays. The SLT uses an emotional tone of voice, affective lexical choices (absolutely loves, love), gaze (her facial expressions are not visible in the video) and a slow rhythm and these are intertwined within the spoken utterance. The long pauses that occur in the middle of the therapist's turn (Lines 6-7) allow the therapist time to plan the next turn constructional unit. Moreover, they allow time also to coconstruct the mutual emotion and intersubjectivity.

Within their conversations, participants utilise shared information (i.e. common ground) about who they are (Clark \& Brennan, 1991; Enfield, 2013). The extent of the common ground varies according to the participants' familiarity and affects the amount and particularity of the information speakers include in their expressions. The wider the common ground is, the less information is needed (Enfield, 2013). Researchers have reported that in aided conversations a familiar partner has been a key factor for the conversations to be successful (e.g., Auer \& Hörmeyer, 2017), but 
sometimes only mutual cultural background may be enough (see Robillard, 1994). Typically, aided communicators rely on a familiar partner's interpretation and apply shortcuts with her or him (Batorowicz et al., 2014). In this excerpt, Jaakko relies on their common ground and uses a referential word US refering to his siblings (Line 5). The SLT recognises the reference and is able to produce a second pair part of the sequence.

In aided conversations, a communication partner's general knowledge on how to use communication books, is one part of the common ground and a prerequisite for the success. When participants are familiar to each other, like Jaakko and his SLT, they know each others' multimodal practices which they have before used in their conversations using communication book.

They can count on each other to apply familiar multimodal practices at the beginning and end the turn, or in navigating in the communication book. Based on their previous experiences, the partner can also adapt his/her help according to an individual need, like in this excerpt the therapist raises Jaakko's hand in turning the page of the communication book (Line 2).

Participants' roles in conversations are determined through their co-operation, such as when participant A acts according to his/her role and participant B accepts it by granting authority to A's role (Stevanovic \& Peräkylä, 2012). One fundamental phenomenon of aided conversations is that a speaking partner assumes the double role as both a conversationalist and a helper (von Tetzchner \& Martinsen, 1996). As the speaking partner attempts to facilitate the progress of the conversation, the aided communicator also needs to accept the speaking partner's role as a helper. It is often difficult for speaking partners to keep the roles separate, and they can dominate the conversation by deciding on topics and leading it by posing questions (Clarke \& Kirton, 2003). During this excerpt, the therapist's helper role is a natural part of the conversation, and she assigns a clear difference between these roles. As the SLT is a helper, she orientates to the communication book, voices the symbol soon after the pointing, and does not insert more than the grammatical influence into her voicing. As the SLT is a conversationalist, she produces the second pair part of the sequence and gazes at Jaakko.

According to Goffman (1981), a speaker can also assume structurally different roles in conversations with speaking people. Goffman divides the role into three possible roles: 1 . The animator is the one who concretely speaks words, 2 . The author is the one who has decided on the content what will be said, and 3. The principal is the one whose values the talk reflects, such as institutional values. For this excerpt, Jaakko produces the aided utterance and he is the author and the principal whereas the SLT is the animator. However, the animator's role is more than that of a person naming the symbol (Sigurd Pilesjö \& Rasmussen, 2011), as in this excerpt, where the therapist also inflects Jaakko's utterance (Line 5), which is a conventional practice in this study.

In addition, Jaakko and his SLT utilise their different ages and many life experiences as one interactional resource. For example, the therapist interprets Jaakko's utterance as though Jaakko is seeking confirmation and convincing of a mother's love for all her children. In doing so, the SLT puts herself in the position as an adult having the right and obligation to convince and explain how mothers feel when a new baby is to be born. The participants' relationship in this situation resembles more an adult child relationship rather than an institutional relationship, even though the therapist is a professional (see Heritage and Drew, 1992).

\section{Synchronising Multimodal Practices}

Iwasaki (2011) describes the process of a social action as multidimensional, where all resources and multimodal practices intertwine, composing an interactional choreography for mutual dance. The previous section described how the participants utilise different interactional resources to formulate 
and ascribe a social action. The present section illuminates how the social actions are achieved through synchronising several modalities in concert. Conversationalists update the process moment by moment completing a social action in combination (Mondada, 2014).

In the second excerpt, we exhibit Jaakko's and his SLT's synchronised multimodal practices at the beginning, the middle and the end of the aided utterance in this particular case, but we also relate the observations of this excerpt to the larger data of the 20 sequences. The aided utterance of this excerpt is divided into two parts: the first involves Jaakko producing the core of the utterance (Lines 1-13), and the second part features his completing it following the therapist's suggestion to tell more (Lines 14-28). In this excerpt, Jaakko produces an aided first pair part, and the SLT interprets it as a statement, which invites a sharing of strong, positive feelings for fairies.

Before this excerpt, Jaakko states that he watches an animation series on television called Winx. The therapist asks whether any one of the five Winx fairies is Jaakko's favourite and Jaakko nods. The excerpt begins when the SLT produces the particle mhmy (Line 1), which receives the information as something new (VISK $\S 798$ ). Jaakko does not continue by naming his favourite fairy; instead, he begins a new first pair part. On the one hand, Jaakko's action is not in line with the therapist's question, as the presupposed answer would be the name of a Winx. On the other hand, Jaakko does not have the Winx fairies' names in his communication book, and he is not able to write them. As a consequence, the nodding must suffice as an answer, and the SLT does not consider it to be a dispreferred response.

\section{Excerpt 2}

$\begin{array}{lll}1 & \text { T: } \\ & \text { jP } \\ & & \\ & & \\ & & \text { jP } \\ & & \text { tG } \\ & & j G\end{array}$
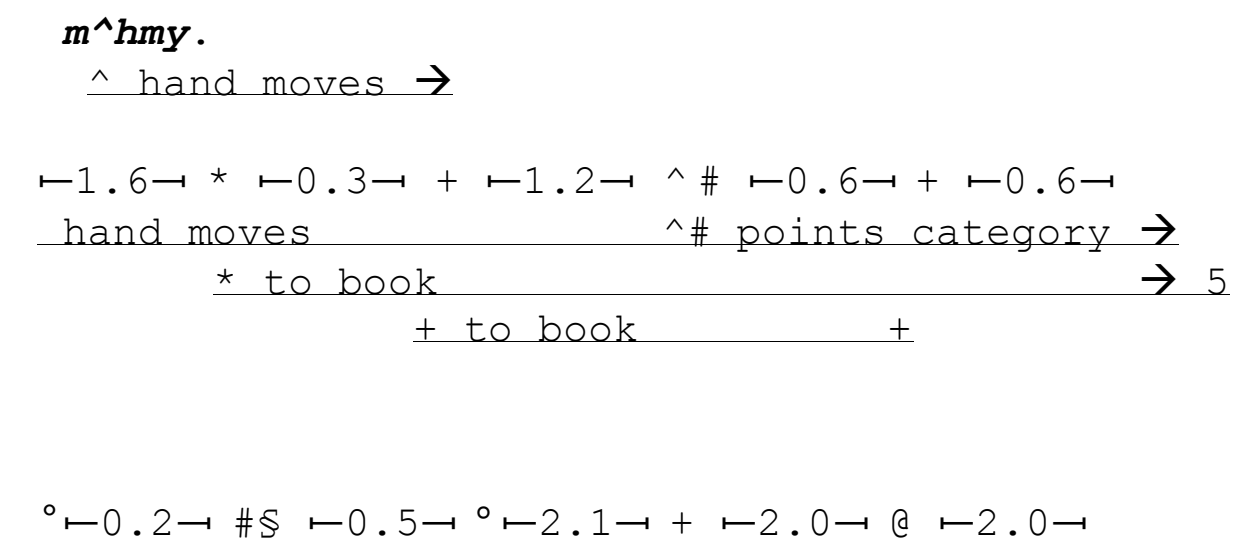

$4 \mathrm{~T}:$ siinä $\vdash 0.3 \multimap \$$

there

tA turns page $s$

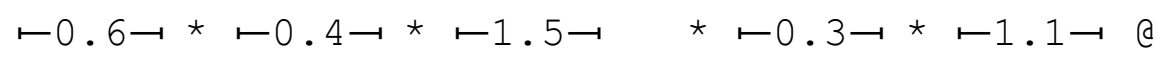


6 T: \$ pistän + ton oven kiinni nii tota. * lähe vaa hakee $I$ put + the door closed so. * go just to seek jG book + follows therapist's motion $\rightarrow$ $t G$ to book $*$ moves $\rightarrow 8$ tA $\$$ stands up to go to door and back $\rightarrow 10$

7 T: merkkiä nii. ei t häiritse noi äänet. a symbol so. does not + disturb those voices. jG follows + book $\rightarrow 9$

$8 \mathrm{~J}: \mapsto 2.2 \multimap \wedge \vdash 1.7 \neg @ \vdash 1.3 \multimap+\vdash 1.3 \multimap+\vdash 3.2 \neg @ * \vdash 2.1 \neg \wedge$

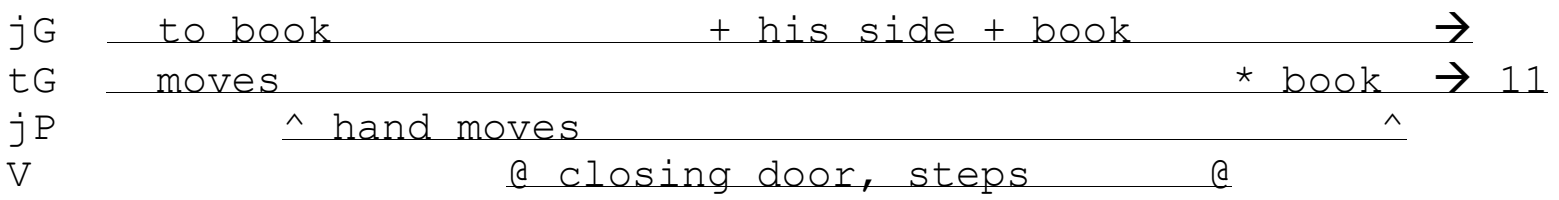

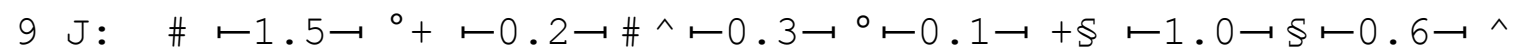
tA comes back to sit $\$$ moves $\rightarrow$ $j G$
book + + book $\rightarrow$ jP tS \#points \#^hand moves I

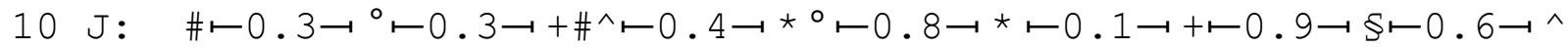
tA moves with chair \$

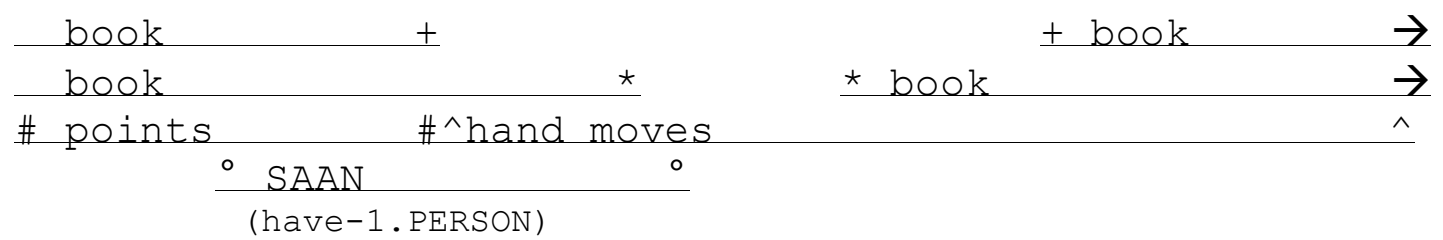

HAVE

$11 \mathrm{~J}: \quad \#$-0.3い+ $j G$

tG

jP

tS

book +

book *

\# points \#

$\mathrm{jH}$

\section{FIT}


$15 \mathrm{~J}: \quad-1.4{ }^{\prime \prime}$

$\mathrm{jH}$ nods "

$16 \mathrm{~T}:$ no ni.

well.

$17 \quad(0.3)$

$18 \mathrm{~J}: \wedge \vdash 0.6 \multimap * \vdash 0.2 \longrightarrow+\vdash 1.4 \neg \wedge \vdash 0.2 \longrightarrow * \vdash 0.4 \longrightarrow * \vdash 0.5 \longrightarrow$

jP hand moves

tG

jG

*book

$\star$ book $\rightarrow 22$

tbook

$\rightarrow$

$19 \mathrm{~J}: \wedge \vdash 1.5 \multimap \S \vdash 2.9 \neg \wedge \# \vdash 1.5 \neg+\vdash 0.4 \longrightarrow$

jG book +

$\mathrm{jP} \wedge$ hand moves $\wedge \#$ points category $\rightarrow 22$

$t A \quad \$$ moves upperbody sideways $\rightarrow$

20 T: mikä $\$$

what

tA moves $\$$

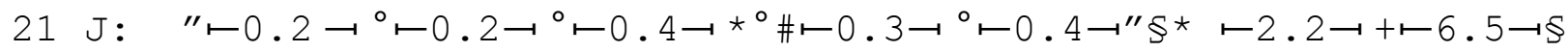

tG $\mathrm{jP}$ points category \# $\#$ \# book

tS $\frac{\circ \mathrm{VA}-}{\text { LE- }} \quad \frac{{ }^{\text {IHMISET }}}{\text { PEOPLE }}$

tA

jG

s turns page $\$$

$+\mathrm{book} \rightarrow 29$

$22 \mathrm{~J}: \wedge \vdash 0.9 \longrightarrow \S \vdash 0.5 \longrightarrow \wedge \# \vdash 0.4 \longrightarrow \S \vdash 0.1 \longrightarrow{ }^{\circ} \# \vdash 0.5{ }^{\circ} \vdash 2.7 \longrightarrow$

$t A$ s $\quad \$$ turns page $\rightarrow 28$

$\operatorname{jP}_{\mathrm{tS}} \wedge$ hand moves $\wedge$ points subcateg \# $\stackrel{\circ \mathrm{HAHMO}}{\circ}^{\circ}$

CHARACTER

23 T: haeksä sanaa $k^{\star} e i j u$

do you seek a word f*airy

tG book $*$

$24 \mathrm{~J}: \quad "$ เ $0.7 \longrightarrow$

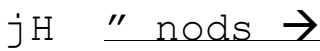

25 т: € j"oo-o.•0.3-jatkaksä silt samalt $y^{\prime \prime}$ es $\vdash 0.3 \longrightarrow$ do you continue with the same opening

jH nods"

$=$ shakes $\rightarrow$

jF $€$ smiles $\rightarrow$ 


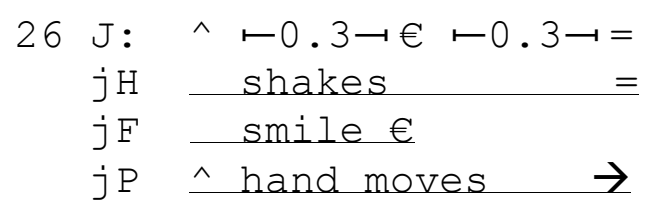

27 T: .het $\$ \vdash 0.4 \neg \wedge \#$ okei $\vdash 0.2 \neg$ keiju

$j \mathrm{P} \quad \begin{gathered}\text { hno } \quad \text { hand moves } \\ \text { turnss }\end{gathered}$

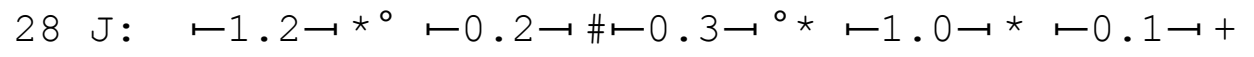

tG book* $\star$ book $\star$

jG book t +

jP $\frac{\text { points }}{\text { jS }}$

GIRL

$29 \quad(0.7)$

$30 \mathrm{~J}: \quad " \vdash 1.7 \multimap "$

$\mathrm{jH}$ "nods "

$31 \quad(1.0)$

32 T: minä saan kohtaus keiju tyttö (0.6) tarkotatko (1.0)

että(0.7) että se tuntuu niinku niin vahvasti kun näkee

semmosen keijun. tai et se on jotenkin niinku ihan

mahtavaa.(1.1) se on semmonen positiivinen tunne.

I have a fit fairy girl (0.6) do you mean (1.0) that (0.7)

that it feels like so strong when you see a fairy like that.

or that it is somehow like quite amazing. (1.1)it is a

positive feeling like that.

$33 \mathrm{~J}:($ (nods and smiles))

34 T: okei.

okay.

\section{Synchronising prebeginnings}

The excerpt begins during the therapist's particle, mhmy, and this is when Jaakko begins to move his hand in order to point to the first symbol of the aided utterance (Line 1). Jaakko's prebeginning practice to move his hand before shifting his gaze was typical of him, but the other boy in our study, Kalle, usually begins by shifting his gaze to an aid or both his gaze and hand move simultaneously. Jaakko's practice of timing the prebeginning in the middle of the SLT's utterance is not the only case in the data, but more often the aided communicators synchronise their prebeginnings with the turn transition relevance place. These observations are supported by Savolainen and associates (submitted) who reported the same practices in conversations using speech generating devices. 
Both therapists in this study were predominantly sensitive to following the aided communicators' prebeginnings through their gaze as well as in the timing of their talk. The SLT in the second excerpt shifts her gaze to the communication book immediately after Jaakko's prebeginning, and this occurs before Jaakko's gaze shift to the book. This practice is found at the beginning of the first and the second part of the aided utterance (Lines 2 and 18). The data also presented three cases that are initiated by Kalle's SLT, who begins a new first pair part, although her gaze is on the communication book, and she can see Kalle moving his finger as the prebeginning of the aided utterance. We observed that the gaze on a communication book did not always mean that the speaking partner was orientated to the aided communicator's turn, which has also been observed in the literature on conversations that use technical communication devices (Norén, Svensson \& Telford, 2013).

\section{Anticipating pointing actions}

As microanalysis allowed us to observe the pointing voicing pairs, we discovered how the pointing and the voicing were intertwined rather than consecutively produced. For example, in the second excerpt, Jaakko points to seven symbols and each time, he begins taking his finger(s) away from a symbol before the SLT has finished voicing the linguistic label. In four cases (Lines 3, 11, 12, 29), Jaakko begins moving his finger after $0.3 \mathrm{~s}$ after the beginning of the voicing at the latest, and in three cases (Lines 13, 22, 23), he initiates the movement of his finger simultaneously with the first sound of the SLT's voicing. The activity of the finger was meaningful for the SLT because it signaled that the voicings were what the aided communicator had intended. It also advanced the progress of the conversation and allowed a shift to the next action. Anticipating the next action is also observed, as Jaakko begins moving his hand towards the symbol, as the therapist is closing the door (Line 8) and during the therapist's page turning (Lines 21 and 25). In the data for this study, this anticipation of pointing was a conventional practice for both aided communicators. They did not wait for room to initiate their pointing, but they synchronised it with the flow of the conversations.

\section{Glancing to communication partner}

During the first excerpt, Jaakko and the SLT coconstruct the aided utterance fluently and look at the communication book during the whole process (from Line 1 to 5). The data for this study also had sequences, in which participants did not look at the book all the time during the coconstruction but glanced at a communication partner. Jaakko maintained his gaze on the book in five sequences out of ten, Kalle did the same in four sequences out of ten, and both speech therapists maintained their gaze on the book in only three sequences out of ten. After analysing the positions of participants' glances at partner, it became apparent that they were not arbitrary and that they were linked to a threat in the progress of the conversations. As evidence, let us now turn to four types of cases in the second excerpt where the participants' gaze practices revealed that something disturbed the flow of a coconstruction process.

During the coconstruction of the aided utterance in the second excerpt, the therapist shifts her gaze to Jaakko seven times, and Jaakko shifts his gaze to the therapist six times. The first type of case was the progress of turns, which means that participants adhere to the rule of "someone's turn must always and exclusively be in progress" (Sacks, et al., 1974, p. 697). The second excerpt contains two turns, in which Jaakko discontinues his turn, and the SLT glances at Jaakko. The first case occurs in line 5, where the therapist has just initiated the opening referred to as HEALTH, and Jaakko looks at the book but does not begin to move his hand for continuing the utterance. The therapist glances at Jaakko twice to register the direction of Jaakko's gaze and orientation. The second case, in which the progress stopped, occurs in line 18. Jaakko is moving his hand towards a 
category symbol, but he discontinues that move, and the therapist immediately checks the focus of Jaakko’s gaze.

The second type of case to discuss was the orientation of participants. The coconstructing process of aided utterance cannot be achieved without contributions by both participants, and it demands both participants' orientation. A conventional practice was that participants looked at the communication book or at each other. The second excerpt contains, however, a rather long phase of multiple actions within a situation, during which the SLT walks to the door, and she sees neither the communication book nor Jaakko's contributions. The therapist's action interrupts the interaction so the participants need to synchronise their actions more than usual. The situation begins in line 5 when Jaakko has not yet begun to move his hand after the SLT had opened the page, and after a 4s pause, the therapist stands up to go to the door to close it. The therapist orients her action as accountable and explains it by noting that she heard noises in the corridor. Jaakko uses his gaze to follow the therapist's motion (Line 6) but returns his gaze to the book after the therapist's advice (Line 7). Jaakko begins to move his hand and orientates to the book, but after 3s, he glances to his side where he hears the sounds of a closing door and steps (Line 8). The therapist is returning, Jaakko points to the symbol "I" and glances at the therapist who is going to sit down (Line 9). Jaakko's glance, which is to ensure the therapist's orientation, receives affirmation when the therapist begins voicing. Jaakko begins preparing for the GET symbol, and simultaneously the therapist begins by shifting her chair to a suitable position and she consequently moves back and forth slightly (Line 9). This movement interrupts Jaakko's orientation on the book, and he glances at the moving therapist (Line 10). During this phase, the therapist is already orientated to the book but glances at Jaakko as he is looking at her. After their short mutual gaze, they both turn their gazes back to the book almost simultaneously. The participants treated this multiple action situation as accountable; Jaakko glanced at the therapist many times to ensure her orientation, and the therapist maintained her orientation on the production process when possible, and explained her disorientation when she walked to the door.

The third type of case involved the progress of the pointing voicing pair. If the pointing is motorically inaccurate, a speaking partner may encounter challenges in seeing the focus of the pointing. Jaakko's manner of pointing to symbols varied during the conversations as well as during the second excerpt. Jaakko pointed at some symbols with his index finger and at some with all his fingers. In line 19, Jaakko moves his hand slowly towards the symbol, but the SLT cannot see the focus and begins to shift her upper body from one side to the other in order to discern the focus of Jaakko's pointing. Jaakko points to the symbol by keeping all his fingers open, and he raises his gaze to the therapist to determine whether the therapist can see the focused symbol. The therapist maintains her gaze on the book and asks What (line 20). Jaakko continues his pointing in the same manner but begins to reinforce it by nodding (Line 21). The therapist initiates voicing LE(isure), but she interrupts it and utters the word PEOPLE, which is next to a leisure symbol. Simultaneously with the second voicing, the therapist looks at Jaakko for assurance that the voicing is correct. Jaakko continues to nod, and the sequence can proceed. An inaccurate pointing was also evident in line 2, when Jaakko shifts his gaze to the therapist after he has reached the category symbol of HEALTH. It seems that the motorically inaccurate pointing slowed the coconstruction process and affected both participants' gaze practices as they negotiated their mutual understanding.

The fourth type of case concerned the progress of the navigation in the communication book. According to a general practice, if the users of a communication book can not turn a page by themselves, they point category symbols and a partner voices the symbol name and turns the page. In line 22 of the second excerpt, Jaakko points to the subcategory referred to as CHARACTER, and the SLT begins turning the pages. However, after $2.7 \mathrm{~s}$, the therapist poses the question of Do you 
seek a word fairy? and shifts her gaze to Jaakko so as to see Jaakko's answer, which involves nodding and smiling (Lines 23-25). By using this question, the SLT anticipates Jaakko's following word to speed up the conversational progress. However, the therapist cannot know whether Jaakko would need some other symbols from the opening CHARACTER, so she still asks Do you continue with the same opening? (Line 25). Jaakko shakes his head, and even though he is still smiling, the therapist treats the head shaking as a response and stops turning pages and states Okay. Fairy. (Lines 25-26). The therapist's first question in this excerpt, which was against the conventional practice, led to the demand for the negotiation of the subsequent line. During the negotiation, the SLT gazed at Jaakko to see his head moves, but Jaakko continued to exhibit an orientation to the progress of the aided utterance by looking at the communication book.

In addition to the four previously introduced types, there were two other cases, in which the participants glanced at their partner during the progress of the turn. 1) When the aided communicators changed the pointing hand (from pointing with left hand to pointing with right hand or vice versa) in the middle of the producing process, the SLTs glanced at the aided communicators probably to ascertain the direction of the orientation. 2) When the SLT began to talk simultaneously or after Kalle's prebeginning, Kalle glanced at the therapist to ensure her orientation. These cases are not shown in excerpts.

The participants gaze practices revealed that the conventional coconstruction of an aided utterance proceeded as follow: 1. The participants shifted their gazes at a book, 2 . The aided communicators pointed a symbol, 3. The speaking partners voiced the label of the symbol (and turned a page), 4 . The same actions were repeated until the last symbol, and then the aided communicators shifted they gaze at a partner, 5. The partners looked at aided communicators and produced an interpretation in their next turn. The participants sensitively monitored the progress of a coconstruction. If there was something unexpected in the process, the participants glanced at a partner. Most of the glances at a communication partner that occurred in the middle of the production process were linked to the interruption of the coconstruction process, but a few cases featured participants who gazed at their partner to invite him or her to smile.

\section{Changing the author of the turn through gaze}

Our microanalysis revealed that the aided communicators timed their gaze around the end of the utterance: immediately after, simultaneously, or even before, the pointing had reached the last symbol, they looked at the SLTs. In the first excerpt, Jaakko begins gazing at the therapist $0.2 \mathrm{~s}$ after his pointing has reached the last symbol (Line 5), and in the second excerpt, Jaakko's gazing begins $0.3 \mathrm{~s}$ after his pointing to the last symbol of the first part of the aided utterance (Line 11). The SLTs in the data for this study followed the aided communicators' gaze, and they usually reached a mutual gaze and began talking simultaneously or slightly after the aided communicators' gaze shift. In the first excerpt, the therapist's gaze shifts simultaneously with Jaakko's gaze, and her talk begins $0.1 \mathrm{~s}$ after their mutual gaze. In the first part of the aided utterance of the second excerpt, the therapist's gaze shifts in $0.5 \mathrm{~s}$, and the talk begins $0.8 \mathrm{~s}$ after Jaakko's gaze. Moreover, Jaakko usually emphasised the end of the utterance by nodding, which began simultaneously with the therapist's voicing (line 11).

At the end of the second part of the aided utterance (Line 28), a deviant practice occurs, in which Jaakko continues to gaze towards the communication book after his pointing to the last symbol, GIRL. At this moment, Jaakko complements the first part of the aided utterance, which is already syntactically complete. The SLT cannot utilise the syntax, and as a consequence, she looks at Jaakko to ensure the possible end of the utterance. While Jaakko looks at the book, the SLT glances at the book for 1s, and after that they achieve a mutual gaze almost simultaneously. After a pause, 
Jaakko begins nodding, which confirms the end of the utterance (line 30). Jaakko's practice of sustaining his unusually prolonged gaze on the book at the end of the aided utterance revealed that Jaakko was unsure regarding the progression of his turn, and the turn transition was delayed. This deviant case as well as how participants interpreted it provided strong evidence for the conventional gaze practice at the end of an aided utterance (see Sidnell, 2013).

\section{Discussion}

This paper describes the multidimensional coconstructing process of aided utterances in conversations that use a communication book. We have demonstrated how participants coconstruct the meaning of aided utterances by utilising six different intertwined interactional resources (selected from the CA literature) which are implemented with synchronised multimodal practices during the coproduction of an aided utterance and in the next turn (Figure 1). The theoretical tool was highly useful in describing the coconstruction of the social action of an aided utterance in this data.

The results of microanalysis provide an enhanced understanding of the temporal, progressive and co-operative nature of the coconstructing process. The interactional resources of the outer circle, in the figure 1, are static or they develop slow during aided conversations, for example, linguistical meaning, but multimodal practices in the inner circle are fast and changing all the time in interaction. In contrast to multimodal practices, interactional resources can be present, even though they are not always explicitly observable in conversation. For example, emotions are always present within the communication partners and they may be, but are not always, evidenced within their interactions. The circles of the figure 1 are drawn separetely, but it does not mean that interactional resources and multimodal practices could be told apart. They have the same purpose to coconstruct a social action, affecting each other, for example, the lack of the common ground probably affects participants' multimodal practices. The importance of representing social action as a flexible application of interactional resources, accomplished by the synchronization of multimodal practices, makes the theoretical tool of this study useful for descriptive research.

\section{Temporality}

According to previous studies, conversations that use nontechnical communication aids are characterized by slow progressivity due to the production process of linguistic meaning through pointing voicing pairs (e.g., Bloch, 2005). The present study confirms the slowness of the production process of an aided utterance, but it was also demonstrated how rare pauses were during the production of an aided utterance. The participants invested their time working toward the progress of the conversations in the same manner as the participants in spoken conversations (see Sacks et al., 1974) or in conversations using speech generating devices (Savolainen et al., submitted). On a few occasions, when a pause occurred during the production process, participants interpreted it as an unexpected action by gazing to their partners. This study also completes the understanding of the temporal nature of pointing voicing pairs (Sigurd Pilesjö \& Rasmussen, 2011). The pointing voicing pairs were not implemented in consecutive order; the multimodal actions were often intertwined or simultaneous, and the conversations were replete with dynamic combinations of these actions for interaction. The participants synchronised their multimodal practices with the interactional context during a conversation through timing and anticipating (see Goodwin, 2000; Mondada, 2014). However, the rapid rhythm and constantly changing multimodal actions may give the impression of them being in a hurry during the conversation. The situations were peaceful, which was also evident in the SLT's long pauses in the middle of second pair part that occurred in both excerpts. The participants were not hurried, and by the pauses, the therapist allowed space for emotional displays and demonstrations of intersubjectivity. These findings have significant 
implications for increasing all communication partners' awareness of the temporal nature of conversations using nontechnical communication aids.

\section{Progression}

All the participants in this study showed continued attention and were sensitive to monitoring each other's contributions during the progress of an aided utterance (see Clark \& Brennan, 1991). For example, at the beginning of an aided utterance, the SLTs closely followed the aided communicators' prebeginnings. The commonly reported prebeginning action in the literature is a gaze shift to the aid (Sigurd Pilesjö \& Rasmussen, 2011), but in this study, Jaakko's first prebeginning involved a hand movement, and his gaze shifted afterwards. To communication partners, it is meaningful to be aware of an aided communicator's initiation of a prebeginning to synchronise their actions with the conversation. Jaakko's prebeginning is a good example of how aided communicators may display individual multimodal practices.

During the coconstructing process, the aided and the speaking communicators synchronised their multimodal practices to facilitate conversational progress. Our findings support the research by Sigurd Pilesjö and Rasmussen (2011) that participants orient to the book during their coproduction. The main orientation of the participants is towards the book, but the monitoring of conversations through glances at the partner is also general for both participants. If the co-construction does not proceed according to the five conventional phases that are introduced in the result section, participants glance at a partner for ensuring the process. By glancing, participants establish a) that both are orientated to the communication book, b) the reason why co-construction does not proceed, c) what symbol is pointed, d) their shared understanding, or e) the end of the utterance, but they also seek emotional intersubjectivity.

The procedure adopted in this study is reproducible. The unexpected progress of the coconstruction and glancing at a partner would warrant further study. By analysing gaze on a partner, we could enhance our understanding of practices which participants themselves consider to be unexpected in conversations that use nontechnical communication aids. This information could help professionals guide the aided communicators and their communication partner in conversations using these aids. However, aided communicators have always used not only conventional practices but individual practices as well in their conversations. For the best results of guiding, professionals might get strong support by utilising video based observations of their client in conversations with different communication partners in everyday interaction.

\section{Co-operation}

Microanalysis is necessary to understand the temporality and progressivity of conversation involving the coconstruction of aided utterances. It helps also to understand the strong co-operation between participants, which the quick progress demands. This all begins in infancy when small babies synchronise their multimodal actions by practicing their co-operation in interaction (see Trevarthen \& Aitken, 2001). The parents of children with disabilities may need professionals to remind them that interactive play, typical of early development, reinforces the basis of their competence in later conversations.

The participants' cooperative construction of conversation in this study was fluent, and the aided utterances that were selected as data included no misunderstandings. Contrary to some previous findings (such as Sundqvist et al., 2010), the SLTs in our study usually gave room for aided communicators to produce aided utterances, the therapists changed their roles between author and animator rather smoothly, and the speaking and the aided communicators were equal authors in the conversations. Premises for the co-operation were good, because the participants shared a mutual 
cultural background, were experienced in using a communication book and had known each other for many years (see Robillard, 1994; Batorowicz et al., 2014). It is impossible to know, how the common ground or the lack of it affects to aided conversations, but the less participants share a common ground, the more they have to show interest in each other and invest in the progress of aided conversations.

In the literature of augmentative communication, the role of a speaking partner is often emphasised for intersubjectivity (e.g., Auer \& Hörmeyer, 2017). The emphasis on the speaking partners' role can mislead and prevent understanding concerning how aided communicators apply the same interactional resources when they produce the social action of the aided utterance as the speaking partners who recognise its meaning. For example, during the first excerpt, Jaakko utilised the larger course of action and common ground to formulate the utterance in the same manner as the speech therapist who interpreted it. This practice allowed Jaakko to produce shorter, quick utterances. In the future, SLTs who provide training in supporting conversation to aided communicators and their communication partners can apply the knowledge of aided communicators' contributions to the production process of social action and also emphasise the responsibility of aided communicators to contribute equally to conversations (see also Savolainen et al., submitted).

\section{Limitations}

Firstly, we are aware that the data for this study are limited due to a lack of information on the symbol to which the aided communicators points. This analysis is based on the speaking partners' voicings, which the aided communicators accept. Secondly, the data for this study were derived from two young aided communicators' conversations using a communication book with their speech and language therapists. To obtain additional information on conversation practices in coconstructing social actions, further CA research is needed on different types of participants who use various types of aids.

\section{Conclusion}

The results of the present study underscore the co-operative process of a conversation that utilizes a communication book from a larger perspective as well as moment by moment. The analysis demonstrates how participants handle multiple interactional resources and simultaneously synchronise different embodied modalities that occur in quick rhythm. The understanding of the temporal, co-operative and progressive nature of conversations that use communication books helps professionals to guide aided communicators and their significant, communicative others in their conversations.

\section{End Notes}

1 AACi communication book is a product of the Valteri Centre of Learning and Consulting of Finland. www.valteri.fi

${ }_{2}$ Pragmatic Organisation Dynamic Display Communication Books is a product of the Cerebral Palsy Education Centre of Glen Waverley. www.cpec.com.au

3 ELAN is a product of the Max Planck Institute for Psycholinguistics of Nijmegen. www.tla.mpi.nl 


\section{References}

Auer, P. and Hörmeyer, I. (2017) Achieving intersubjectivity in augmented and alternative communication (AAC): Intercorporeal, embodied and disembodied practices. In C. Meyer, J. Streeck and S. Jordan (ed.) Intercorporeality. Emerging Socialities in Interaction 323-360. Oxford: University Press.

Batorowicz, B., Campbell, F., von Tetzchner, S., King, G. and Missiuna, C. (2014) Social participation of school-aged children who use communication aids: the views of children and parents. Augmentative and Alternative Communication 30: 237-251. doi:10.3109/07434618.2014.940464

Binger, C. and Light, J. (2008) The morphology and syntax of individuals who use AAC: Research review and implications for effective practice. Augmentative and Alternative Communication 24: 123-138. doi: 10.1080/07434610701830587

Bloch, S. (2005) Co-constructing meaning in acquired speech disorders: Word and letter repetition in the construction of turns. In K. Richards and P. Seedhouse (ed.) Applying Conversation Analysis 38-55. London: Palgrave Macmillan.

Clark, H. and Brennan, S. (1991) Grounding in communication. Perspectives on socially shared cognition 13: 127-149.

Clarke, M. and Wilkinson, R. (2013) Communicative competence in children`s peer interaction. In N. Norén, C. Samuelsson and C. Plejert (ed.) Aided Communication in Everyday Interaction 23- 57. Guildford: J\&R Press Ltd.

Clarke, M., Bloch, S. and Wilkinson, R. (2013) Speaker transfer in children's peer conversation: Completing communication-aid-mediated contributions. Augmentative and Alternative Communication 29: 37-53. doi:10.3109/07434618.2013.767490

Clarke, M. and Kirton, A. (2003) Patterns of interaction between children with physical disabilities using augmentative and alternative communication systems and their peers. Child Language Teaching \& Therapy 19: 135-151. doi:10.1191/0265659003ct248oa

Drew, P. and Heritage, J. (1992) Talk at work: Interaction in Institutional Settings. Cambridge: Cambridge University Press.

Enfield, N. J. (2013) Relationship thinking: Agency, Enchrony, and Human Sociality. Oxford: University Press.

Goffman, E. (1981) Forms of Talk. Oxford: Basil Blackwell.

Goodwin, C. (2000) Action and embodiment within situated human interaction. Journal of Pragmatics 32: 1489-1522. doi: 10.1016/S0378-2166(99)00096-X

Heath, C. and Luff, P. (2013) Embodied action and organizational activity. In J. Sidnell and T. Stivers (ed.) The handbook of Conversation Analysis 283-306. Chichester: Wiley-Blackwell.

Hedvall, P. and Rydeman, B. (2010) An activity systemic approach to augmentative and alternative communication. Augmentative \& Alternative Communication 26: 230-241. doi:10.3109/07434618.2010.528795

Hidecker, M. J. C., Paneth, N., Rosenbaum, P. L., Kent, R. D., Lillie, J., Eulenberg, J. B., Chester, K, Johnson, B, Evatt, M. and Taylor, K. (2011) Developing and validating the communication function classification system for individuals with cerebral palsy. Developmental Medicine \& Child Neurology 53: 704-710. doi: 10.1111/j.1469-8749.2011.03996.x

Higginbotham, D. J. and Wilkins, D. P. (1999) Slipping through the timestream: Social issues of time and timing in augmented interactions. Constructing (in) competence: Disabling evaluations in clinical and social interaction 2: 49-82.

Iwasaki, S. (2011) The multimodal mechanics of collaborative unit construction in Japanese conversation. In J. Streeck, C. Goodwin and C. LeBaron (ed.) Embodied Interaction: Language and the Body in the Material World, 106-120. Cambridge: University Press.

Koivunen, A. (2012) Kommunikointikansio keskustelutilanteessa: apuvälineen ja kumppanin toiminnan tarkastelua. [Interaction by means of a dynamic communication book - a look at the 
communication aid and the communication partner]. Master's thesis. Retrieved from https://helda.helsinki.fi/handle/10138/235815.

Levinson, S. C. (2013) Action formation and ascription. In J. Sidnell and T. Stivers (ed.) The Handbook of Conversation Analysis 103-130. Chichester: Wiley-Blackwell.

Lloyd, L., \& Blischak, D. (1992). AAC terminology policy and issues update. Augmentative and Alternative Communication, 8(2), 104-109. 10.1080/07434619212331276153

Mondada, L. (2014). The local constitution of multimodal resources for social interaction. Journal of Pragmatics 65: 137-156. doi: 10.1016/j.pragma.2014.04.004

Nevile, M. (2015) The embodied turn in research on language and social interaction. Research on Language and Social Interaction 48: 121-151. doi: 10.1080/08351813.2015.1025499

Norén, N., Samuelsson, C. and Plejert, C. (2013) Dialogical perspectives on aided communication. In N. Norén, C. Samuelsson and C. Plejert (ed.) Aided Communication in Everyday Interaction 1-22. Guildford: J\&R Press Ltd.

Norén, N. and Sigurd Pilesjö, M. (2016) Supporting a child with multiple disabilities to participate in social interaction: The case of asking a question. Clinical Linguistics \& Phonetics 30: 790811. doi:10.1080/02699206.2016.1213883

Norén, N., Svensson, E. and Telford, J. (2013) Participants' dynamic orientation to folder navigation when using a VOCA with a touch screen in talk-in-interaction. Augmentative \& Alternative Communication 29: 20-36. doi:10.3109/07434618.2013.767555

Robillard, A. (1994) Communication problems in the intensive care unit. Qualitative Sociology 17: 383-395.

Ruusuvuori, J. (2013) Emotion, affect and conversation. In J. Sidnell and T. Stivers (ed.) The Handbook of Conversation Analysis 330-349. Chichester: Wiley-Blackwell.

Sacks, H., Schegloff, E. A. and Jefferson, G. (1974) A simplest systematics for the organization of turn-taking for conversation. Language 50: 696-735. doi:10.2307/412243

Savolainen, I., Klippi, A., Tykkyläinen, T. and Launonen, K. (submitted) Structure of turntransitions and participants' practices in aided conversations.

Schegloff, E. A. (2007) Sequence Organization in Interaction. Cambridge: University Press.

Sigurd Pilesjö, M. (2013) On the use of bodily action and vocalizations as resources and methods when claiming and completing turns in aided interaction. In N. Norén, C. Samuelsson and C. Plejert (ed.) Aided Communication in Everyday Interaction 1-22. Guildford: J\&R Press Ltd.

Sigurd Pilesjö, M. and Norén, N. (2017) Teaching communication aid use in everyday conversation. Child Language Teaching and Therapy 33: 241-253. doi: 10.1177/026565901770220

Sigurd Pilesjö, M. and Rasmussen, G. (2011) Exploring interaction between a non-speaking boy using aided AAC and his everyday communication partners: Features of turn organizing and turn design. Journal of Interactional Research in Communication Disorders 2: 183-213. doi: 10.1558/jircd.v2i2.183

Sidnell, J. (2013) Basic conversation analytic methods. In J. Sidnell and T. Stivers (ed.) The Handbook of Conversation Analysis 77-100. Chichester: Wiley-Blackwell.

Stevanovic, M. and Peräkylä, A. (2012) Deontic authority in interaction: The right to announce, propose, and decide. Research on Language and Social Interaction 45: 297-321. doi: $10.1080 / 08351813.2012 .699260$

Stevanovic, M. and Weiste, E. (2017) Conversation-analytic data session as a pedagogical institution. Learning, Culture and Social Interaction 15: 1- 17. doi:10.1016/j.lcsi.2017.06.001

Sundqvist, A., Plejert, C. and Ronnberg, J. (2010) The role of active participation in interaction for children who use augmentative and alternative communication. Communication \& Medicine 7: 165-175. doi:10.1558/cam.v7i2.165

Stivers, T and Sidnell, J. (2005) Introduction: multimodal interaction. Semiotica 156: 1-20. doi:10.1515/semi.2005.2005.156.1 
Todman, J., Alm, N., Higginbotham, J. and File, P. (2008) Whole utterance approaches in AAC. Augmentative and Alternative Communication 24: 235-254. doi: 10.1080/08990220802388271

Trevarthen, C. and Aitken, K. J. (2001) Infant intersubjectivity: Research, theory, and clinical applications. Journal of Child Psychology and Psychiatry and Allied Disciplines 42: 3-48.

Ferm, U., Ahlsen, E. and Bjorck-Åkesson, E. (2013) Spontaneous communication with blisssymbolics between mother and her daughter at home: What do they talk about and how? In N. Norén, C. Samuelsson and C. Plejert (ed.) Aided Communication in Everyday Interaction 281-314. Guildford: J\&R Press Ltd.

VISK = Auli Hakulinen, Maria Vilkuna, Riitta Korhonen, Vesa Koivisto, Tarja Riitta Heinonen \& Irja Alho (2004): Iso suomen kielioppi. [Big Finnish Grammar] Helsinki: Suomalaisen Kirjallisuuden Seura. Retrieved from: http://scripta.kotus.fi/visk 12.3.2018

von Tetzchner, S. and Martinsen, H. (1996) Words and strategies: Conversations with young children who use aided language. In S. von Tetzchner and H. Jensen (ed.) Augmentative and Alternative Communication: European Perspectives 65-88. London: Whurr. 


\section{Appendix: Transcript Notation}

The capital letter in the beginning of the numbered line refers to the participants's turn.

$\mathrm{J}=$ Jaakko

$\mathrm{T}=$ speech and language Therapist

In the top line are durations $(\vdash 1.0 \multimap)$ and order of the multimodal practices which Jaakko and therapist use in co-constructing the turn. The beginning and the end of one multimodal action is signed with the same symbols.

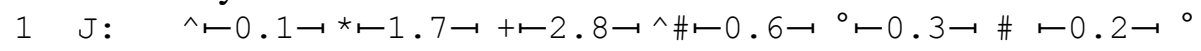

In the lower lines, the practices are described each in own line, and small letters $(j / t)$ refers to participants, and capitals refers to the type of the multimodal action.

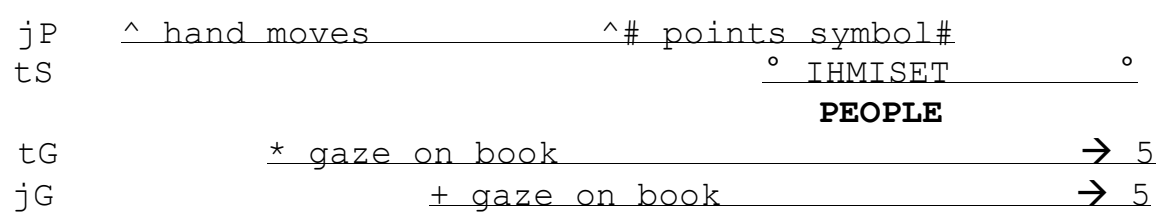

The capitals and the symbols for the multimodal actions are:

\begin{tabular}{|c|c|c|}
\hline $\mathrm{P}$ & $\wedge$ & Moving hand for purpose to point to a symbol. \\
\hline & $\#$ & Pointing to a symbol. \\
\hline $\mathrm{S}$ & $\circ$ & $\begin{array}{l}\text { Therapist voices a SYMBOL, translations are bolded, } \\
\text { abbreviations in glossing: }\end{array}$ \\
\hline & & INF $\quad$ infinitive \\
\hline & & 1 st person ending \\
\hline & & 3rd person ending \\
\hline & & PAR $\quad$ partitive \\
\hline G & * & Therapist's gaze on a communication book. \\
\hline & + & $\begin{array}{l}\text { Aided communicator's gaze on a communication book. } \\
\text { NB When a gaze is not transcribed, its focus is on a partner! }\end{array}$ \\
\hline A & $\$$ & Activity is described in transcription. \\
\hline $\mathrm{H}$ & $"$ & Head: Nodding. \\
\hline & $=$ & Head: Shaking \\
\hline $\mathrm{F}$ & $€$ & Aided communicator's smile \\
\hline & $\$$ & Therapist's laugh \\
\hline $\mathrm{V}$ & & Voices from environment \\
\hline & $\rightarrow$ & Practice is continuing. \\
\hline & l speech & Naturally spoken elements, which are not the voicings of symbols. \\
\hline & & Translations are bolded. \\
\hline & & Fall in intonation. \\
\hline( & & One-second pause \\
\hline
\end{tabular}

